\title{
The Criteria for Software Quality in Information System: Rasch Analysis
}

\author{
Wan Yusran Naim Wan Zainal Abidin ${ }^{1}$, Zulkefli Mansor ${ }^{2}$ \\ Faculty of Information Science and Technology \\ National University of Malaysia, Jalan Bangi \\ 43000 Bangi, Selangor DE, Malaysia
}

\begin{abstract}
Most of the organization uses information system to manage the information and provide better decision making in order to deliver high quality services. Due to that the information system must be reliable and fulfill the quality aspect in order to accommodate organization's need. However, some of the information system still facing problems such as slow response time, problem with accessibility and compatibility issues between hardware and software. These problems will affect the acceptance and usage of the information system especially for non-computing users. Therefore, this study was aimed to investigate the factors that significantly contribute to the quality of software for information system. A survey was carried out by distributing a set of questionnaires to 174 respondents who are involved in development of software for information system. The data was analyzed using Rasch Measurement Model since it provides reliability of respondents and instruments. The result indicates that 30 factors had significantly contributed to the quality of software for information system and of these, six factors are under functionality, five for reliability, ten for usability, five for efficiency, two for compatibility and two for security. It is hoped that by identifying these factors, system developers can seriously consider of enhancing the quality of software for information system projects. In future, these factors can be used to develop an evaluation tool or metrix for quality aspects of software for information system projects.
\end{abstract}

Keywords-Information system; quality of software; Rasch measurement model; evaluation; factors

\section{INTRODUCTION}

Information system is important in developing successful and competitive organizations that can deliver high quality products and services to customers [1,2]. It helps improving the flow of information and work processes in organisation, thus can enhance the decision-making processes. Even though the information system provides benefits to the organization, it has been highlighted some weaknesses that contributed to the failure of fulfilling the quality aspects of a system such as slow response time, access problem, difficulties in using system, unavailability and incompatibility between hardware and software $[3,4]$.

As a result, if these problems continuously faced by the users, it will cause less acceptance and usage of information systems. Thus, it leads to the poor delivery of services and products and finally will damage the organization's reputation. Therefore, system developers should focus to strengthen the software quality aspect of information system.
There are many software quality models currently being used to evaluate quality of software products. So, this paper will firstly show the comparisons between these models in the literature review section. The advantages and disadvantages of these models are also investigated. Based on these analyses, the ISO 25010 model was adopted in this study. Next, the paper discusses the methodology used in the study, which includes the descriptions of constructs and the explanation of the Rasch model used to perform data analysis. The paper also shows and discusses findings based on main assumptions of the Rasch Model for selection of items such as item fit, unidimensionality and local independence.

The study is very important in that it enables the improvement towards the information system development by having a guideline on factors that significantly improve the software quality aspect. It also serves as an additional reference towards the improvement of software quality in information systems.

However, this study only focuses on the human resource information system widely used in the planning and management of human resource. It also considers the software quality factors from the users' perspective only because software quality issues are usually related to this perspective.

\section{LITERATURE REVIEW}

Various models have been developed to measure software quality for information system such as the McCall, Boehm, FURPS, Dromey, ISO 9126 and ISO 25010 models. Each model was developed based on a certain unique principal or concept. These models explain about different aspects of software characteristics [5]. These models can be viewed from a user perspective, a manufacturing perspective or a product perspective. Table I below shows the comparison between these models.

These models also have the advantages and disadvantages of their own as stated in Table II below.

\section{A. Factors Influencing Software Quality}

This study also analyzed previous studies to identify the quality dimensions and factors that were used to measure the software quality. Table III shows the type of information systems that were analyzed. 
TABLE. I. COMPARISON OF SOFTWARE QUALITY MEASUREMENT MODELS

\begin{tabular}{|c|c|c|c|c|c|c|}
\hline Model & McCall & Boehm & FURPS & Dromey & ISO 9126 & ISO 25010 \\
\hline Author & Jim McCall & Barry W. Boehm & Hewlett Packard & R. Geoff Dromey & ISO & ISO \\
\hline Year & 1977 & 1978 & 1992 & 1995 & 2001 & 2011 \\
\hline Description & $\begin{array}{l}\text { - bridge the gap between } \\
\text { user and system } \\
\text { developer } \\
\text { - Consider users' view } \\
\text { and developer priorities } \\
\text { - Focus on accurate } \\
\text { measurement of high- } \\
\text { level characteristics } \\
\text { - based on } 3 \text { perspectives } \\
\text { - Product Revision, } \\
\text { Product Operation and } \\
\text { Product Transition } \\
\end{array}$ & $\begin{array}{l}\text { - define software } \\
\text { quality through a } \\
\text { set of qualitative } \\
\text { characteristics and } \\
\text { metrics } \\
\text { - based on hierarchy } \\
\text { arranged according } \\
\text { to characteristic } \\
\text { level - high, } \\
\text { moderate and } \\
\text { primitive }\end{array}$ & 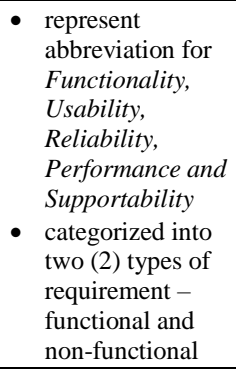 & $\begin{array}{l}\text { - based on product } \\
\text { quality perspective } \\
\text { - focus on } \\
\text { relationship } \\
\text { between software } \\
\text { product } \\
\text { characteristics and } \\
\text { software quality } \\
\text { attributes }\end{array}$ & $\begin{array}{l}\text { developed based on } \\
\text { McCall and Boehm } \\
\text { models } \\
\text { to align the } \\
\text { evaluation of } \\
\text { software or system } \\
\text { product using ISO } \\
\text { quality model } \\
\text { - list of internal and } \\
\text { external } \\
\text { characteristics of a } \\
\text { software product } \\
\end{array}$ & $\begin{array}{l}\text { - } \text { improvement to } \\
\text { ISO } 9126 \\
\text { Model } \\
\text { - } \text { two (2) } \\
\text { additional } \\
\text { quality factors } \\
- \\
\text { compatibility } \\
\text { and security }\end{array}$ \\
\hline $\begin{array}{l}\text { Measurement } \\
\text { Factor }\end{array}$ & $\begin{array}{l}\text { - Correctness } \\
\text { - Reliability } \\
\text { - Usability } \\
\text { - Efficiency } \\
\text { - Integrity } \\
\text { - Maintenance } \\
\text { - Testability } \\
\text { - Flexibility } \\
\text { - Portability } \\
\text { - Reusability } \\
\text { - Interoperability }\end{array}$ & $\begin{array}{l}\text { - Portability } \\
\text { - Reliability } \\
\text { - Efficiency } \\
\text { - Usability } \\
\text { - Testability } \\
\text { - Understandability } \\
\text { - Flexibility }\end{array}$ & $\begin{array}{ll}\text { - } & \text { Functionality } \\
\text { - } & \text { Usability } \\
\text { - } & \text { Reliability } \\
\text { - } & \text { Performance } \\
\text { - } & \text { Supportability }\end{array}$ & $\begin{array}{ll}\text { - } & \text { Efficiency } \\
\text { - } & \text { Understandabilit } \\
& \text { - } \\
\text { - } & \text { Reliability } \\
\text { - } & \text { Process Maturity } \\
\text { - } & \text { Maintenance } \\
\text { - } & \text { Portability }\end{array}$ & $\begin{array}{l}\text { - } \text { Functionality } \\
\text { - } \text { Reliability } \\
\text { - Usability } \\
\text { - } \text { Efficiency } \\
\text { - } \text { Paintenance } \\
\text { Portability }\end{array}$ & $\begin{array}{l}\text { - Functionality } \\
\text { - Reliability } \\
\text { - Usability } \\
\text { - Efficiency } \\
\text { - Compatibility } \\
\text { - Security } \\
\text { - Maintenance } \\
\text { - Portability }\end{array}$ \\
\hline
\end{tabular}

TABLE. II. AdVAntages And Disadvantages of Software Quality MEasurement Models

\begin{tabular}{|c|c|c|c|}
\hline No. & Model & Advantage & Disadvantage \\
\hline 1. & McCall & - Having evaluation criteria & $\begin{array}{l}\text { - Overlapping of components } \\
\text { - Software quality measured subjectively, as it is based on responses } \\
\text { of Yes or No } \\
\text { - The model does not consider the functionality so that the user's } \\
\text { vision is diminished } \\
\text { - No consensus about what high level quality factors are important } \\
\text { Each quality factor is positively influenced by a set of quality } \\
\text { criteria, and the same quality criterion impacts several quality } \\
\text { factors. If an effort is made to improve one quality factor, another } \\
\text { quality factor may be degraded. } \\
\text { No standards, no methods and no tools to measure the quality } \\
\text { factors. }\end{array}$ \\
\hline 2. & Boehm & $\begin{array}{l}\text { - Including factors related to hardware } \\
\text { - Easy to understand and learn }\end{array}$ & $\begin{array}{ll} & \text { Lack of criteria } \\
\text { - } & \text { Very difficult to apply in practice }\end{array}$ \\
\hline 3. & FURPS & $\begin{array}{l}\text { - Separating functional and non-functional requirements } \\
\text { - Can be used as both product requirements as well as in the } \\
\text { assessment of product quality }\end{array}$ & - Not considering portability \\
\hline 4. & Dromey & - Applicable to different systems & - Incomprehensiveness \\
\hline 5. & ISO 9126 & $\begin{array}{l}\text { - } \text { Having evaluation criteria } \\
\text { - } \quad \text { Separating internal and external quality } \\
\text { - } \quad \text { Unify and quantify different views of quality requirements } \\
\text { - } \quad \text { Having a single universal model makes it easier to compare one } \\
\text { product with another. } \\
\text { - The characteristics defined are applicable to any kind of software } \\
\text { while providing consistent terminology for software product } \\
\text { quality. } \\
\text { covers all crucial characteristics such as hierarchical structure; } \\
\text { criteria for evaluation; comprehensive expression and terms; } \\
\text { simple and accurate definitions; and one to between various layers } \\
\text { of model } \\
\text { widely used in the software engineering community and has been } \\
\text { adapted to different domains and contexts } \\
\text { easy to use and understand by its users. }\end{array}$ & $\begin{array}{l}\text { - The traceability of the software and the consistence of the data are } \\
\text { not represented in the model } \\
\text { - The model does not include measurements methods } \\
\text { - There is no consensus regarding what is a top-level quality-factor } \\
\text { and what is more concrete quality criterion }\end{array}$ \\
\hline 6. & ISO 25010 & $\begin{array}{l}\text { - } \quad \text { the most recent and updated model } \\
\text { - } \quad \text { Improvement to ISO } 9126 \\
\text { - } \quad \text { Additional of security attribute }\end{array}$ & \\
\hline
\end{tabular}


TABLE. III. TYPES OF INFORMATION SYSTEM

\begin{tabular}{|c|c|c|c|}
\hline No. & Type of System & Author & Reference \\
\hline 1. & Enterprise Information System & $\begin{array}{l}\text { Hu and Wu (2016) } \\
\text { Green and Robb (2014) } \\
\text { Esaki (2013) }\end{array}$ & $\begin{array}{l}\mathrm{A} \\
\mathrm{B} \\
\mathrm{C}\end{array}$ \\
\hline 2. & Knowledge Management System & Wu and Wang (2006) & $\mathrm{J}$ \\
\hline 3. & e-Government System & Cohen and Eimicke (2003) & $\mathrm{M}$ \\
\hline 4. & e-Learning System & $\begin{array}{l}\text { Hassanzadeh, Kanaani \& Elahi (2012) } \\
\text { Bhuasiri et al. (2012) } \\
\text { A.K.M. Najmul Islam (2011) } \\
\text { Padayachee et al. (2010) } \\
\text { Lin (2007) }\end{array}$ & $\begin{array}{l}\mathrm{D} \\
\mathrm{E} \\
\mathrm{F} \\
\mathrm{G} \\
\mathrm{I}\end{array}$ \\
\hline 5 . & Generic Information System & $\begin{array}{l}\text { Gable et al. (2008) } \\
\text { Hellstén and Markova (2006) } \\
\text { Iivari (2005) } \\
\text { Poon \& Wagner (2001) } \\
\text { Goodhue, Thompson \& Goodhue (1995) } \\
\text { Srivinasan (1985) }\end{array}$ & $\begin{array}{l}\mathrm{H} \\
\mathrm{K} \\
\mathrm{L} \\
\mathrm{N} \\
\mathrm{O} \\
\mathrm{P}\end{array}$ \\
\hline
\end{tabular}

TABLE. IV. SOFTware QuALITY MEASUREMENT FACTORS

\begin{tabular}{|c|c|c|c|c|c|c|c|c|c|c|c|c|c|c|c|c|c|c|}
\hline \multirow{2}{*}{ No. } & \multirow{2}{*}{ Quality Factor } & \multicolumn{16}{|c|}{ Author } & \multirow{2}{*}{$\Sigma$} \\
\hline & & $\mathrm{A}$ & $\mathrm{B}$ & $\mathrm{C}$ & $\mathrm{D}$ & $\mathrm{E}$ & $\mathrm{F}$ & $\mathrm{G}$ & $\mathrm{H}$ & $\mathrm{II}$ & $\mathrm{J}$ & $\mathrm{K}$ & $\mathrm{L}$ & $\mathrm{M}$ & $\mathrm{N}$ & $\mathrm{O}$ & $\mathrm{P}$ & \\
\hline 1 & Easy to use & & $\bullet$ & $\bullet$ & $\bullet$ & $\bullet$ & & $\bullet$ & & & $\bullet$ & $\bullet$ & & & & & & 7 \\
\hline 2 & Response & & $\bullet$ & & & $\bullet$ & & $\bullet$ & & $\bullet$ & $\bullet$ & & $\bullet$ & & & & & 6 \\
\hline 3 & Reliability & $\bullet$ & $\bullet$ & $\bullet$ & $\bullet$ & $\bullet$ & & & & & & & & & & & $\bullet$ & 5 \\
\hline 4 & Easy to access & & & & $\bullet$ & & & & & & & $\bullet$ & $\bullet$ & & $\bullet$ & & & 4 \\
\hline 5 & Functionality & - & & $\bullet$ & & $\bullet$ & & & & & & & & & & & & 3 \\
\hline 6 & User friendly & & & & $\bullet$ & & & & & & $\bullet$ & & & & $\bullet$ & & & 3 \\
\hline 7 & Fulfill user requirement & & & & - & & & & - & & & $\bullet$ & & & & & & 3 \\
\hline 8 & Interactive & & & & - & - & & & & & & & & & - & & & 3 \\
\hline 9 & Security & & $\bullet$ & & $\bullet$ & & & & & & & & & & & & & 2 \\
\hline 10 & Maintenance & & & $\bullet$ & $\bullet$ & & & & & & & & & & & & & 2 \\
\hline 11 & Integration & & & & $\bullet$ & & & & & & & & $\bullet$ & & & & & 2 \\
\hline 12 & Flexibility & & & & $\bullet$ & & & & & & & & $\bullet$ & & & & & 2 \\
\hline 13 & Structural design & & & & $\bullet$ & & & $\bullet$ & & & & & & & & & & 2 \\
\hline 14 & Updated information & & & & & & & $\bullet$ & $\bullet$ & & & & & & & & & 2 \\
\hline 15 & Recoverability & & & & & & & $\bullet$ & & & & & $\bullet$ & & & & & 2 \\
\hline 16 & Learnability & & & & & & & & & & & $\bullet$ & & & & $\bullet$ & & 2 \\
\hline 17 & Data and System Accuracy & & & & & & & & & & & $\bullet$ & & & & & $\bullet$ & 2 \\
\hline 18 & Portability & & & $\bullet$ & & & & & & & & & & & & & & 1 \\
\hline 19 & Efficiency & & & $\bullet$ & & & & & & & & & & & & & & 1 \\
\hline 20 & System Stability & & & & & & & & & & $\bullet$ & & & & & & & 1 \\
\hline 21 & Data Integration & & & & & & & & & & & & & $\bullet$ & & & & 1 \\
\hline 22 & Aesthetic & & & & $\bullet$ & & & & & & & & & & & & & 1 \\
\hline 23 & Personalization & & & & $\bullet$ & & & & & & & & & & & & & 1 \\
\hline 24 & Attractive & & & & $\bullet$ & & & & & & & & & & & & & 1 \\
\hline 25 & System Speed & & & & $\bullet$ & & & & & & & & & & & & & 1 \\
\hline 26 & Internet quality & & & & & $\bullet$ & & & & & & & & & & & & 1 \\
\hline 27 & Memory space & & & & & & $\bullet$ & & & & & & & & & & & 1 \\
\hline 28 & System Integration & & & & & & & $\bullet$ & & & & & & & & & & 1 \\
\hline 29 & Standard Compliance & & & & & & & - & & & & & & & & & & 1 \\
\hline 30 & Fault tolerance & & & & & & & $\bullet$ & & & & & & & & & & 1 \\
\hline 31 & Parallel terms & & & & & & & $\bullet$ & & & & & & & & & & 1 \\
\hline 32 & Consistent terms & & & & & & & $\bullet$ & & & & & & & & & & 1 \\
\hline 33 & Understandability & & & & & & & $\bullet$ & & & & & & & & & & 1 \\
\hline 34 & Information arrangement & & & & & & & $\bullet$ & & & & & & & & & & 1 \\
\hline 35 & Access by many users & & & & & & & $\bullet$ & & & & & & & & & & 1 \\
\hline 36 & Accurate solution & & & & & & & & & $\bullet$ & & & & & & & & 1 \\
\hline 37 & Data integration & & & & & & & & $\bullet$ & & & & & & & & & 1 \\
\hline 38 & Usability & & & & & & & & & & & $\bullet$ & & & & & & 1 \\
\hline 39 & Language & & & & & & & & & & & & $\bullet$ & & & & & 1 \\
\hline 40 & Availability & & & & & & & & & & & & & & & $\bullet$ & & 1 \\
\hline 41 & Response to user & & & & & & & & & & & & & & & $\bullet$ & & 1 \\
\hline 42 & Solution alternative & & & & & & & & & & & & & & & & $\bullet$ & 1 \\
\hline
\end{tabular}


Based on the analysis, it was found that various quality factors used differently according to the types and functions of an information system. Several factors are widely used by researchers such as easy to use, response and reliability. This may be because these three factors reflect the basic features required to ensure the quality of the system. Table IV shows the list of quality factors.

\section{METHODOLOGY}

In this study, a quantitative approach was used by conducting a survey to achieve its objectives and questions.

\section{A. Participants}

A total of 174 civil servants in Public Service Department (PSD), Putrajaya participated in this study. They comprise of 67 males $(39 \%)$ and females $(61 \%)$. They were divided into 2 categories of services, where 79 or $45 \%$ were in the Professional and Management category, and 95 (55\%) were in the Support Services category.

\section{B. Instrument}

This study employs a self-developed 39-items questionnaire consisting of six constructs that represent quality factors, namely the Functionality, Reliability, Usability, Efficiency, Compatibility and Security (Table V). The scale is 5 points Likert-type, where participants are required to give their response on a Strongly DisagreeDisagree - Slightly Agree - Agree - Strongly Agree pattern.
As stated above, the constructs and items (quality factors) are gathered based on the analysis of previous studies related to software quality. To ensure that the constructs and items are valid and can be used to collect data effectively, the development of survey is very important. It must be done systematically to ensure it fulfils the study objectives. After identifying constructs and items, a suitable scale is selected and the testing of item validity and instrument reliability are performed. Expert view is obtained and content validation is also done since they are also important elements in making sure the instrument is relevant.

\section{Data Analysis}

Rasch Model is used to analyze data from the respondents. The model refers to an idea, principal, guideline or technique that enables measurement of the latent trait [6]. It basically separates individual capabilities and instrument's quality. This model assumes that individual response towards an item is only influenced by individual capabilities and item difficulties [7]. The ability of the Rasch Model as an analytical instrument is proved by its application in various research areas including management and social science. This model prevents researchers in social sciences area from making a raw and blurred observation and undertakes definitive actions with realistic accuracy and clear quality control [8]. In this study, the WinStep software is used to perform the Rasch analysis.

TABLE. V. DESCRIPTION OF CONSTRUCTS

\begin{tabular}{|c|c|c|}
\hline Construct & Description & No. of Items \\
\hline Functionality & $\begin{array}{l}\text { Software capability to provide functions that fulfil the user requirement of human resource } \\
\text { information system. }\end{array}$ & 8 \\
\hline Reliability & $\begin{array}{l}\text { Software capability to maintain the performance level for a period to support the human } \\
\text { resource management. }\end{array}$ & 7 \\
\hline Usability & $\begin{array}{l}\text { Software capability to be understood, learned and used to implement the human resource } \\
\text { management. }\end{array}$ & 13 \\
\hline Efficiency & $\begin{array}{l}\text { Software capability to produce desired performance in assisting user to perform human } \\
\text { resource management functions effectively. }\end{array}$ & 7 \\
\hline Compatibility & $\begin{array}{l}\text { Software capability to ensure efficient performance while sharing common environment and } \\
\text { resources and/or exchange information with other products that perform the same functions. }\end{array}$ & 2 \\
\hline Security & $\begin{array}{l}\text { Software capability to ensure secure transactions while performing human resource } \\
\text { management functions effectively. }\end{array}$ & 2 \\
\hline Total & & 39 \\
\hline
\end{tabular}

\section{FINDINGS}

This study considers main assumptions of the Rasch Model for selection of items such as item fit, unidimensionality and local independence. It also considers other aspects such as reliability index, separation index, and the respondent-item map.

\section{A. Item Fit}

Two criteria are used to measure the good fit-ness of items, namely the Outfit $M N S Q=\mathrm{y}$, where $0.5<\mathrm{y}<1.5$ and Outfit Z-standard (Zstd) $=\mathrm{z}$, where $-2<\mathrm{z}<2$ for acceptance of items [9]. Although the analysis shows that 6 items do not fulfil the criteria, they are considered as important items. Thus, these items are reviewed and modified to suit the measurement objective.

\section{B. Unidimensionality}

The raw variance explained by measures is 53.8 percent, which is close to the expected model value of 57.5 percent. This exceeds the minimum value required of 40 percent. The unexplained variance in the first contrast is 7.5 percent, less than the maximum value of 15 percent. This shows that the instrument can measure in one standard dimension and thus is able to achieve its measurement objective.

\section{Local Independence}

Ten pairs of items with the largest standardized residual correlations values have been identified. One pair of items, A1 - Provides accurate human resource information and A2 Provides updated human resource information has a value of 0.72 , indicating these items are overlapped. However, since these items measure different characteristics (accurate and 
updated information) and both characteristics are important, both are retained in the actual questionnaire.

\section{Reliability Index}

The Cronbach Alpha index is valued at 0.96. This shows that the instrument is highly reliable. The respondent reliability index is 0.93 , and item reliability index is 0.98 . This result indicates that there is enough sample and the instrument is suitable to measure the respondents' capabilities and item difficulties.

\section{E. Separation Index}

The respondent separation index is 3.67 , and the item separation index is 7.70. Index value between three and four indicates good value while the value more than five indicates excellent value [6]. This shows that the items can separate the respondents based on their capabilities and items based on the difficulties.

\section{F. Respondent-Item Distribution Map}

The respondent-item map shows the distribution of items based on difficulties with the distribution of respondents' capabilities along the logits scale (see Fig. 1).

Overall, most respondents are above the $\mathrm{Mean}_{\text {item }}=0.00$ logits. This indicates that almost all of them can answer the questionnaire. There are also a larger number of respondents above the $\mathrm{Mean}_{\text {respondent }}=2.08$ logits. It also indicates that the respondents are competent enough to determine the criteria influencing the software quality of an information system.

The difficulty measurement value ranges between +3.12 logits and -0.96 logits. The item distribution shows item B $7 \mathrm{r}$ Software problem affects the system performance as the most difficult to be agreed item while item E1 - All data must be integrated with each other as the easiest item to be agreed.

Based on the analysis, there were 30 items that are under the $\mathrm{Mean}_{\mathrm{item}}=0.00$, indicating the number of criteria that contribute significantly to the software quality of the human resource information system. Table VI shows the significant items.

The gap in the item distribution map is also examined to determine whethe.r the items are enough to evaluate the capabilities of all respondents. The result shows there are gaps between items B6r (2.75 logits) and C8r (2.10 logits) and D2r (1.56 logits) and C10 (0.75 logits). These gaps indicate that there are not enough items to measure higher level of respondents' capabilities. This is also highlighted by the respondents and item distribution above the line, where the number of items is comparatively smaller compared to the number of employees.

Thus, further study is required to develop more difficult items that can measure respondents with higher capabilities.

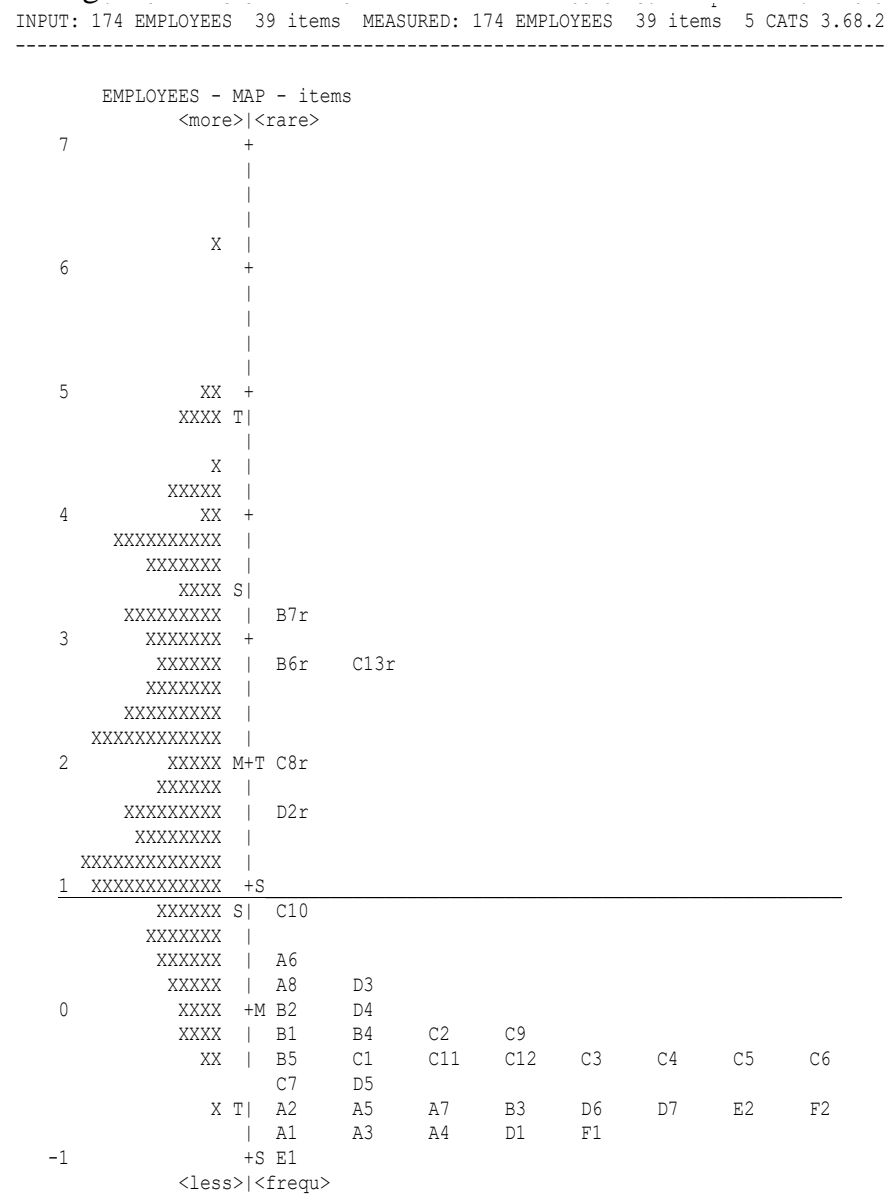

Fig. 1. Respondent-Item Distribution Map. 
TABLE. VI. SIGNIFICANT ITEMS FOR EACH QUALITY FACTOR

\begin{tabular}{|l|l|}
\hline Quality Factors & Significant Items \\
\hline Functionality & A1, A2, A3, A4, A5, A7 \\
\hline Reliability & B1, B2, B3, B4, B5 \\
\hline Usability & C1-C7, C9, C11, C12 \\
\hline Efficiency & D1, D4, D5, D6, D7 \\
\hline Compatibility & E1, E2 \\
\hline Security & F1, F2 \\
\hline
\end{tabular}

\section{DISCUSSION}

This section will discuss the findings from the respondent and item point of view.

\section{A. Respondent}

Overall, most respondents are placed above the Mean $_{\text {Item }}$ value. This shows that almost all respondents can answer the questionnaire to determine the criteria for information system capabilities. Number of respondents above the Mean Respondent are also bigger than that of below the mean value. This shows that the respondents possess experience in utilizing information system in their work thus are aware of the criteria required to ensure good software quality in information system.

Apart from that, there is also a group of respondents that can be considered the most competent. They are the experts and possess huge experience in information system development. Based on their experience, they agreed that all software quality criteria are important and should be considered when developing an information system.

\section{B. Item Distribution}

Based on Fig. 1, the item distribution map shows that item B $7 r$ - The system performance affected when there is software problem is the least agreeable item. This indicates the respondents' view that if the software quality is good, the information system will not be affected and can maintain its performance although there might be problem with the software. Meanwhile, the item E1 - All data in the system must be integrated is the most agreeable one, indicating that the respondents agreed the criteria is very important in ensuring the best software quality in information system.

Besides, there are 30 items below the Mean $_{\text {Item }}$ value, placed under the category of most agreeable items. It shows that these criteria are widely used dan emphasized in determining software quality in an information system. It also shows that the respondents agreed these items significantly contribute to the information system software quality.

For Construct A (Functionality), there are six items under the category of most agreeable. This shows that these items are deemed very important and significant in ensuring the best software quality in information system. Two (2) items, A6 Capable to perform prediction towards a certain scenario and A8 - Capable to perform what-if analysis on various scenarios are placed under the moderate category. This shows that both criteria are becoming more important today and system developers should consider these aspects when developing or modifying an information system to further enhance its capabilities in assisting stakeholders to ensure accurate and comprehensive decisions are made. This is in line with the study done by [10] that discussed and suggested the framework for intelligent human resource information system.

As for Construct B (Reliability), five items are under the most agreeable category, indicating that these items are very important in determining the software quality. Respondents also agreed that item B2 - Suggest accurate solution based on user requirement is becoming more important in assisting the decision-making process. The least agreeable items are item B6r - Information visualization in certain formats only and B7r - The system performance affected when there is software problem. It shows that the respondents agreed an excellent information system should be capable to visualize information in various formats, depending on the alternative and requirement of users. This is because there is no one format that can fulfil different requirements of the users comprehensively. This is in line with the information technology advancement, where Business Intelligence (BI) is considered when developing an information system. Apart from that, an excellent system should be capable of recovering quickly from any software problem and maintain its performance. In an era where time is essence, decision making must be made quickly thus it is very critical to have an information system that is always stable and maintain the best performance. In the context of software reliability, different models are needed to evaluate the software reliability at different levels of development [11]. This is because software reliability is a very critical factor and should be evaluated thoroughly. Reliability issues do not only affect the system performance but can also cause complete failure of the system.

Under Construct C (Usability), ten items are placed in the most agreeable category. This shows that these criteria are very important and widely used in determining information system software quality. This finding is in line with the study by [12] which states that the usability factor is very important in ensuring the efficiency and effectiveness of health information system. However, two (2) items are the least agreeable. One of them is item C8r - User spends a long time in learning to use the system, indicating that the respondents do not agree if users require a long time to learn how to use a system. Another item is C13r - User needs ICT knowledge to use the system. With the advancement in ICT resulting in the development of more intelligent information system, the system should be easier to use by anybody, including those without detailed technical and ICT knowledge.

For Construct D (Efficiency), six items are in the agreeable category. This indicates that the respondents agreed with most items under this construct. It is very important to have an efficient system that provides fast service and has information presentation design that is understood by the users. An 
efficient system should also be capable to maintain its performance while being accessed by many users at the same time. For example, in public sector there are information systems that are developed for the benefit of the whole civil servants. In this construct, only item D2r - Takes a long time to process users' request such as generating report or analyzing information that is the least agreeable. This is because an information system is designed to help users doing their work. Therefore, they need a system that would be able to give response to a request and process it within a short period of time.

As for Construct E (Compatibility), both items are most agreed by respondent. This shows that both items are very important in the development of information system. The capability of data and system integration with different environment or system is among the basic characteristics of a good and efficient system and can ensure real time accurate information [13]. Information system integration is also very important for the success of e-Government [14] For example, integration of several systems in different agencies will enable business license applications to be processed and approved in a short time.

Lastly for Construct F (Security), both items F1 and F2 are also in the most agreeable category. This shows that the security aspect is very important in an information system. Nowadays, the introduction and application of Internet of Things (IoT) in intelligent devices enables the connectivity of the devices to the Internet [15]. But this has also exposed the devices to security risks such as information leakages or theft. So, it is very important to ensure an information system is secure and prevent system or process failure.

\section{CONCLUSION}

Overall, this study has successfully identified the factors and criteria influencing the software quality of information system. By identifying these criteria, it will serve as a guideline to improve the software aspect of an information system and ensure that the system has the capability and quality at its best.

However, technological advancements today has brought about the needs for intelligent information systems that are able to perform more complex functions. Thus, there is a need for future research to look into other software quality factors and criteria that will give advanced capabilities to the system.

System developers also play an important role in ensuring that an information system is able to perform as required. Their inpu is equally important so as to enable the software quality to be assessed comprehensively. Therefore, it is also recommended for future research to take into account the perspective of system developers.

Information systems are being used in various fields to assist in decision making and strategic planning. Each field requires different capabilities and technical requirements. So it is also recommended that future works should look into different types of information system. This will further contribute to the improvement of the system and software quality.

\section{ACKNOWLEDGMENT}

This paper was funded by Fundamentals Research Grant Scheme (FRGS), Ministry of Education Malaysia under project code FRGS/1/2018/ICT04/UKM/02/11.

\section{REFERENCES}

[1] Oprea, M., "MAS_UP-UCT: A multi-agent system for university course timetable scheduling," International Journal of Computers, Communications \& Control, 1, 2007, 94-102. doi:10.1590/S141565552003000100014.

[2] Masrek, M. N., "Reinventing Public Service Delivery: The Case of Public Information Systems Implementation in Malaysia," International Journal of Public Information Systems, 1, 2009, 9-15.

[3] Poon, P. and Wagner, C., "Critical success factors revisited: Success and failure cases of information systems for senior executives," Decision Support Systems, 30(4), 2001, 393-418. doi:10.1016/S01679236(00)00069-5

[4] Elkadi, H., "Success and failure factors for e-government projects: A case from Egypt," Egyptian Informatics Journal, 14(2), 2013, 165-173. doi:10.1016/j.eij.2013.06.002

[5] El-far, I. K. and Whittaker, J. A., "Model-based Software Testing," 122, 2001.

[6] Azrilah Abdul Aziz, Mohd Saidfudin Masodi, and Azami Zaharim, "Asas Model Pengukuran Rasch," Penerbit Universiti Kebangsaan Malaysia. 2013.

[7] Bond, T. and Fox, C. M., "Applying the Rasch Model Fundamental Measurement in the Human Science," hlm.Second Edi. 2007.

[8] Wright, B. D. and Mok, M. M. C., "An Overview of the Family of Rasch Measurement Models. Introduction to Rasch Measurement," 2004, 1-24.

[9] Nopiah, Z. M., Rosli, S., Baharin, M. N., Othman, H., and Ismail, A., "Evaluation of pre-assessment method on improving student's performance in complex analysis course," Asian Social Science, 8(16), 2012, 134-139. doi:10.5539/ass.v8n16p134

[10] Masum, A.-K., Beh, L.-S., Azad, A.-K., and Hoque, K., "Intelligent human resource information system (i-HRIS): A holistic decision support framework for HR excellence," International Arab Journal of Information Technology, 15(1), 2018, 121-130.

[11] Anila, M., Sirisha, N., and Karthik, R., "Software reliability models - A comparative study. Proceedings of the International Conference on Intelligent Sustainable Systems," ICISS 2017, (Iciss), 2018, 1152-1154.

[12] Alshamari, M., "Usability Factors Assessment in Health Information System," Intelligent Information Management, 08(06), 2016, 170-180.

[13] Wiemann, S., Brauner, J., Karrasch, P., Henzen, D., and Bernard, L., "Design and prototype of an interoperable online air quality information system," Environmental Modelling and Software, 79, 2016, 354-366.

[14] Siti Istianah Mahdzur; and Juhana Salim, "Information Systems Integration Factors In Organization: Towards Government Information Systems Sustainability," Journal of Theoretical and Applied Information Technology, 71(2), 2015, 235-250.

[15] Kumar, S. A.; Vealey, T.; and Srivastava, H., "Security in internet of things: Challenges, solutions and future directions," Proceedings of the Annual Hawaii International Conference on System Sciences, 2016March (January), 2016, 5772-5781. 